\title{
PERMUKIMAN BARU HEMAT ENERGI DI SUDIROPRAJAN
}

\author{
Rychell Lyaputera ${ }^{1)}$, Budi A. Sukada ${ }^{2)}$ \\ 1)Program Studi S1 Arsitektur, Fakultas Teknik, Universitas Tarumanagara, rychelllyaputera@gmail.com \\ 2) Program Studi S1 Arsitektur, Fakultas Teknik, Universitas Tarumanagara, budisukada@yahoo.com
}

Masuk: 03-07-2021, revisi: 15-08-2021, diterima untuk diterbitkan: 23-10-2021

\begin{abstract}
Abstrak
Pada dasarnya manusia hidup sekarang dengan bantuan alam dan mahluk hidup lain yang turut menjaga keseimbangan ekologi. Permasalahan yang sedang dihadapi oleh bumi ini, salah satunya ketidakseimbangan ekologi, dimana manusia bertambah namun lahan atau tempat tinggal serta makanannya mengalami penurunan tetap. Salah satu akibatnya adalah banyak berkembangnya permukiman kumuh. Tujuan dari desain ini adalah untuk memperlihatkan solusi merancang permukiman dengan kualitas hidup yang lebih baik daripada permukiman kumuh. Target sasaran desain merupakan masyarakat yang memiliki kualitas hidup menengah ke bawah atau yang kurang mampu, yang berada dipermukiman kumuh. Metodologi yang digunakan dalam perancangan ini adalah survei disertai wawancara secara langsung dan studi literatur. Adapun metode perancangannya sendiri menerapkan sistem Greenship home v.1.0, dengan penekanan pada aspek hunian hijau, khususnya pengudaraan dan pencahayaan alami, energi terbarukan, serta ruang terbuka hijau. Sasaran-akhir perancangan berupa rumah-susun dengan fasilitas yang mendukung kegiatan warga, memiliki ruang terbuka hijau, ruang terbuka dengan perkerasan untuk kegiatan luar-ruang serta energi terbarukan dalam rangka mengurangi emisi. Untuk itu tersedia perangkat panil-surya di bangunan rumah susun dan bangunan serba guna, pada bangunan rumah-susun terdapat fasilitas daur-ulang air hujan dan air limbah. Selain itu tersedia juga fasilitas pengolahan sampah anorganik dalam rangka mengurangi sampah plastik, untuk dijual dan hasilnya menjadi tambahan pendapatan warga. Dengan melakukan hal kecil ini, bisa membantu pengehematan energi, karena sampah anorganik menjadi sesuatu yang berguna yang bisa digunakan kembali, mulai menggunakan listrik yang berasal dari tenaga surya, dan menghemat dan bijak dalam penggunaan air.
\end{abstract}

Kata kunci: Berkelanjutan; Energi Terbarukan; Hunian Vertikal; Ruang Terbuka

\begin{abstract}
Basically, the present human being lives their life by the support of nature and other beings to maintain ecological balance. The problems that the world is facing today, among others, is that it has become imbalance due to the increasing numbers of people when the stock of land and food resources are decreasing. One of the result of such imbalance is the increasing number of slum areas. Hence, the aim of this project is to show solution of housing design that provides better quality of life. The design targets are people who have a lower-middle quality of life or those who are less fortunate, who live in slums. The design methodology within this housing design is a simple survey and unstructured questionnaires, together with literature studies. The design method, on the other hand, is to apply the Greenship home v.1.0 system, featuring green settlement aspects, particularly natural ventilation and lighting, renewable energy, and green open space. The ultimate target is a vertical housing with facilities that support activities of the occupants, having gree open space as well as hard openspace for outdoor sport activities, along with renewable system of energy to decrease the emission. Hence, there are solar panels at vertical housing and the multi-purpose building, recycle system of rain water and waste. There are also facilities of un-organic trash to degrade plastic waste and to process it into selling goods that may add the income of occupants. By doing this little thing, people can help save energy, because inorganic waste becomes something useful that can be reused, start using electricity from solar power, and save and be wise in the use of water.
\end{abstract}

Keywords: Outdoor; Renewable Energy; Sustainable; Vertical Housing 


\section{PENDAHULUAN}

\section{Latar Belakang}

Pada saat ini semakin hari masyarakat dan sekitarnya semakin berkembang, seiring waktu berjalan alam pun semakin berkurang, dan itu berdampak pada perubahan ekosistem alam yang sudah berada lama sebelum adanya manusia. Hal ini juga berdampak pada manusia yang sehari-hari menjalankan hidup dengan mengandalkan alam. Manusia banyak memanfaatkan alam, membuat keseimbangan ekosistem menjadi tidak stabil. Banyak keuntungan-keuntungan yang diperoleh manusia, tanpa memikirkan mahluk hidup yang ada di alam.

Dengan adanya upaya menyeimbangkan ekologi, maka perlu adanya upaya untuk memperbaiki ekologi, salah satunya adalah memperbaiki kualitas hidup masyarakat khususnya yang tertempat tinggal dipermukiman kumuh, dimana merupakan salah satu permasalahan yang sedang ada. Dimana menempati tempat tinggal seperti itu merusak lingkungan, dan dinilai tidak sehat karena banyaknya penyakit yang akan timbul. Perbaikan permukiman kumuh merupakan salah satu langkah untuk meningkatkan kualitas masyarakat dalam menjalani kehidupan untuk bisa bertahan hidup.

Berhemat energi dalam kehidupan sehari-hari diperlukan, dengan memanfaatkan sampah anorganik sebagai barang yang digunakan kembali, pengolahan air limbah dan air hujan sebagai tindakan bijak dalam mengolah sisa air yang digunakan maupun pemanfaatan untuk digunakan kembali, serta adanya pemanfaatan sinar matahari sebagai listrik, dimulai dari suatu permukiman yang berada di daerah Sudiroprajan, Solo. Permukiman ini termasuk kumuh, dan kurang adanya perhatian pada lingkungan dilihat dari bagaimana rumah-rumah disana berdempetan dan sempit, serta memiliki jalan yang kurang layak.

\section{Rumusan Permasalahan}

Manusia semakin banyak memanfaatkan alam dengan kurang bijaksana, dan menimbulkan efek buruk terhadap alam dan mahluk hidup lainnya. Hal ini membuat gaya hidup manusia sekarang kurang baik, dan perlu adanya perubahan agar bisa menyeimbangkan kembali antara alam dengan manusia dan mahluk hidup lainnya, sehingga adanya peran arsitektur dalam menyeimbangkan ekologi terutama padadaerah hunian dengan memperbaiki permukiman yang masuk dalam kategori kumuh, dengan menambahkan kegiatan yang mendukung untuk hidup dalam penghematan energi, seperti pengolahan air limbah dan air hujan, sampah anorganik yang bisa diolah menjadi barang yang bermanfaat seperti tasatau kantung belanja, dompet, taplak meja dan kerajinan tangan berbahankan plastic bekas sampah rumah tangga, seperti sampah plastic detergen, dan lain sebagainya.

\section{Tujuan}

Perbaikan permukiman kumuh ini bertujuan untuk membantu masyarakat yang tinggal di daerah Sudiroprajan bisa memperbaiki kualitas hidup dan sekaligus bisa membantu menyeimbangkan ekologi, melalui gaya hidup ini untuk masa depan dan generasi selanjutnya. Selain itu masyarakat bisa lebih memperhatikan kesehatan, dengan adanya perbaikan permukiman kumuh ini.

\section{KAJIAN LITERATUR}

\section{Pembangunan Berkelanjutan (sustainable development)}

a. Pengertian pembangunan berkelanjutan dalam Stockholm United Nation Conference on Human Enviromental pada tahun 1972 atau dikenal sebagai Deklarasi Stockholm adalah sebagai berikut:

segala sumber daya alam di bumi, termasuk udara, air, tanah, flora dan fauna terutama contoh yang mewakili bagian ekosistem alam, harus dijaga supaya aman untuk kepentingan generasi sekarang dan masa depan melalui perencanaan atau manajemen yang sesuai dan hati-hati.

b. Menurut Brundtland Report dalam sidang PBB tahun 1987,

pembangunan berkelanjutan atau dalam bahasa Inggris sering disebut sustainable development merupakan proses pembangunan yang berprinsip untuk memenuhi kebutuhan sekarang tanpa mengorbankan kebutuhan generasi yang akan datang.

c. Dalam World Commission On Enviromental Development (WCED) pada tahun 1987

dirumuskan bahwa pengertian pembangunan berkelanjutan adalah pembangunan yang berusaha 
memenuhi kebutuhan hari ini tanpa mengurangi kemampuan generasi mendatang untuk memenuhi kebutuhannya.

\section{Rumah susun (UU No. 16 Tahun 1985, tentang Rumah Susun)}

Bangunan gedung bertingkat yang dibangun dalam suatu lingkungan yang terbagi dalam bagian-bagian yang distrukturkan secara fungsional dalam arah horisontal maupun vertikal dan merupakan satuansatuan yang masing-masing dapat dimiliki dan digunakan secara terpisah terutama untuk tempat hunian yang dilengkapi dengan bagian bersama, benda bersama dan tanah bersama.

Satuan rumah susun, bagian bersama, benda bersama dan tanah bersama :

1. Satuan rumah susun adalah rumah susun yang tujuannya digunakan sebagai tempat hunian.

2. Bagian bersama adalah bagian rumah susun yang dimiliki secara tidak terpisah untuk pemakaian bersama.

3. Benda bersama adalah benda yang bukan merupakan bagian rumah susun tetapi yang dimiliki secara tidak terpisah untuk pemakaian bersama.

4. Tanah bersama adalah sebidang tanah yang digunakan atas dasar hak bersama secara tidak terpisah yang di atasnya berdiri rumah susun dan ditetapkan batasnya dalam persyaratan ijin bangunan.

\section{Rumah Ramah Lingkungan (Green Home)}

Menurut GBCI (Green Building Council Indonesia), 2011, Rumah merupakan bangunan yang berfungsi sebagai tempat tinggal atau hunian dan sarana pembinaankeluarga. Konsep rumah ramah lingkungan sudah sepatutnya memenuhi dasar layak huni dengan memenuhi persyaratan keselamatan bangunan dan kecukupan minimum luas bangunan sertakesehatanpenghuninya. Rumah ramah lingkungan merupakan rumah yang bijak dalam menggunakanlahan, efisiendan efektif dalam penggunaan energi maupun dalam menggunakan air, memperhatikankonservasi material sumber daya alam serta sehat dan aman bagi penghuni rumah. Perawatan rumahyang ramah lingkungan dan aman juga merupakan faktor penting, karena keberlanjutan dari rumah ramah lingkungan harus disertai dengan perilaku ramah lingkungan oleh penghuninya. Pemahaman konsep akan rumah ramah lingkungan merupakan faktor utama yang harus diprioritaskan untuk menghindari kesalahpahaman akan anggapan bahwa rumah ramah lingkungan atau green home merupakan rumah yang memerlukan biaya perawatan tinggi ataupun merupakan rumah yang hanya memiliki banyak lahanhijau.

\section{Penghematan energi}

Tindakan mengurangi jumlah penggunaan energi. Menghemat energi berarti tidak menggunakan energi listrik untuk suatu hal yang tidak berguna. Penghematan energi dapat dicapai dengan penggunaan energi secara efisien di mana manfaat yang sama diperoleh dengan menggunakan energi lebih sedikit, ataupun dengan mengurangi konsumsi dan kegiatan yang menggunakan energi. Penghematan energi dapat menyebabkan berkurangnya biaya, serta meningkatnya nilai lingkungan, keamanan negara, keamanan pribadi, serta kenyamanan.

Dalam pengehematan energi, bisa menggunakan energi alternatif. Energi alternative merupakan energy pengganti yang dapat mengganti peranan minyak bumi (Dwianto Setyawan, 2009). Energi alternatif berasal dari energi yang dapat diperbaharuhi contohnya energi air, energi sinar matahari, panas bumi, gelombang laut atau bio, energi aternatif yang dikembangkan memakai sumber energi yang tersedia di alam dan tidak akan habis.

\section{METODE}

Metode yang digunakan penulis selama mendesain merupakan survei disertai wawancara tidak terstruktur dan melalui studi literatur dan dilanjutkan metode analisis, dimana setelah melakukan studi literatur dan melakukan survei untuk mendapatkan fakta, dilakukan analisis untuk mendapatkansintesis dan diakhiri dengan kesimpulan. Metode desain yang digunakan mengacu pada Greenship Home V.1.0. Greenship Home V.1.0 memiliki kriteria dalam mendesain hunian untuk mewujudkan rumah ramah lingkungan (green home): 
(1) Pengaturan mengenai tata guna lahan yang memuat mengenai area hijau, infrastruktur, aksesbilitas, pengendalian hama, upaya pengurangan emisi, dan pengurangan limpasan air hujan. Berdasarkan dari penjelasan ini, permukiman yang akan didesain membutuhkan ruang terbuka hijau;

(2) Efisiensi energi dan konservasi yang memuat mengenai pentingnyapencahayaan dan pengudaraan secara alami serta mendorong penggunaan elektronik hemat energi, dan penggunaan energi terbarukan. Pada desain rumah susun, akan memanfaatkan pencahayaan dan pengudaraan lebih maksimal;

(3) Mengenai konservasi air dimana membicarakan mengenai hemat dalam penggunaan air serta bisa mengolah air limbah dan upaya penggunaan air hujan sebagaiair bersih. Mengolah dan menggunakan kembali air libah atau air hujan sebagai air bersih yag bisa digunakan untuk menyirami tanaman dan sebagainya;

(4) Sumber dan siklus material dimana bermaksud untuk adanya upaya penggunaan material ramah lingkungan. Menggunakan bahan-bahan tahan lama dan tidak perlu adanya perawatan khusus;

(5) Kualitas udara dan kenyamanan udara upaya dalam pengendalian sirkulasi udara bersih serta pencahayaan alami. Salah satu upaya dalam menghemat energi, karena adanya pemanfaatan udara dan pencahayaan alami;

(6) Manajemen lingkungan bangunan dimana membicarakan mengenai sistem berkelanjutan. Mengolah sampah anorganik menjadi barang siap pakai dan bermanfaat bagi warga atau masyarakat sekitar, seperti tas atau kantung belanja, dompet, taplak meja dan lain sebagainya.

\section{DISKUSI DAN HASIL}

Berawal dari isu mengenai ketidakseimbangan ekologi yang terjadi, akibat dari ketidakseimbangan ekologi salah satunya timbulnya permukiman kumuh. Permukiman kumuh ini terbentuk karena semakin meningkat pertumbuhan penduduk, namun lahan untuk tinggal semakin berkurang. Akibatnya adalah dimana menempati lahan untuk beberapa rumah, membuat kondisi rumah tidak sesuai dengan kebutuhan. Permukiman kumuh juga berkaitan dengan urbanisasi yang terjadi, urbanisasi terjadi karena adanya peningkatan gaya hidup untuk bertahan hidup.

Disamping memperbaiki permukiman kumuh, berdasarkan metode maka harus adanya upaya hemat energi, seperti adanya penggunaan udara dan cahaya matahri sebagai sumber pengudaraan alami dan pencahayaan alami, maka dalam desain dibuat secara terbuka agar udara dan cahaya matahari bisa masuk kedalam ruangan. Hal ini upaya dalam pengehematan energi, dan mengurangi penggunaan listrik secara tidak teratur.

\section{Tapak}

Mengawali isu dengan permukiman kumuh, maka tapak yang sesuai dengan isu adalah tapak dengan kondisi yang kumuh dan kurang layak atau bahkan tidak layak tinggal. Penulis memilih tapak yang berada di kota Solo, di daerah Sudiroprajan. Lokasi ini tercatat lokasi permukiman kumuh, berdasarkan data dalam Dinas Pekerjaan Umum dan Penataan Ruang.

Tapak proyek berada tepat di Balong, Sudiroprajan, di Jalan Kapten Mulyadi. Tapak memiliki luas 14.729 $\mathrm{m}^{2}$. Terdiri dari Balong gang VI, Balong gang V, Balong gang IV, dan Balong gang III. Menurut data Peta Perencanaan Pola Ruang Kota Surakarta, tata guna lahan merupakan pemukiman padat tinggi.

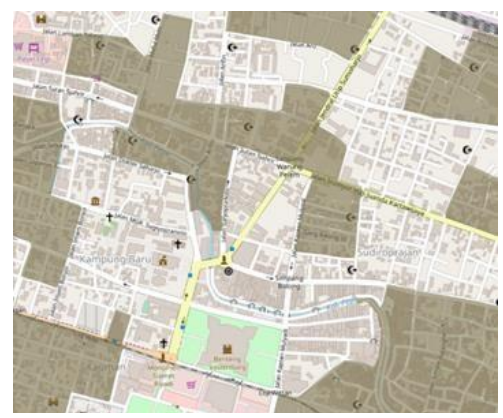

Gambar 1. Kawasan Permukiman Kumuh

Sumber : Informasi Tata Ruang Infrastruktur dan Perencanaan Kota Surakarta, 2017 


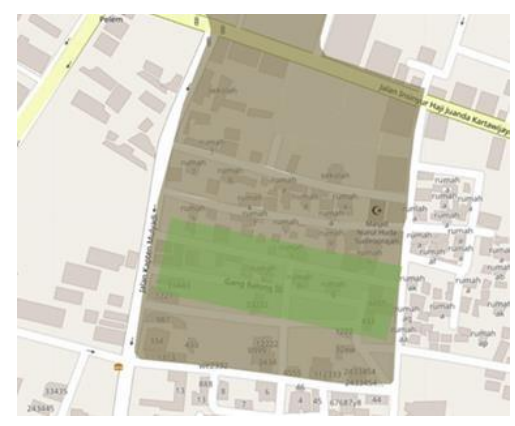

Gambar 2. Lokasi Proyek

Sumber : Informasi Tata Ruang Infrastruktur dan Perencanaan Kota Surakarta, 2017

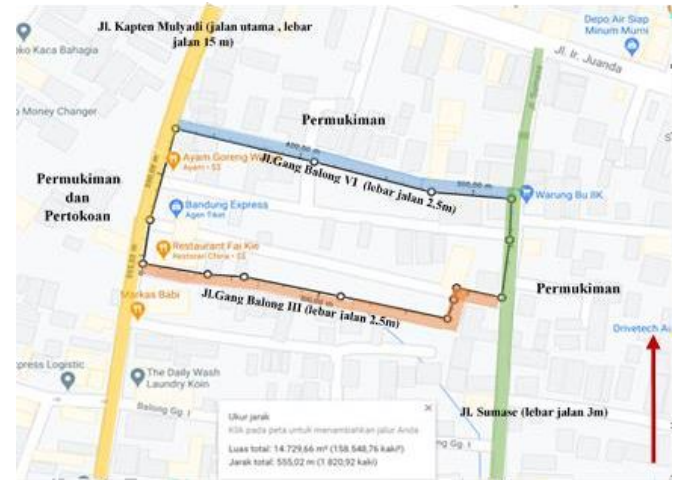

Gambar 3. Tapak Terpilih

Sumber : google maps, 2021

Tapak memilliki KDB 60\% yang berarti lahan yang boleh dibangun seluas $8.837 \mathrm{~m}^{2}, \mathrm{KDH} 40 \%$ dengan lahan hijau seluas $5.891 \mathrm{~m}^{2}$, dengan KLB 3. Tapak berbatasan dengan permukiman dan pertokoan.

Menurut analisis penulis, dari aspek pencahayaan bangunan dengan muka sisi lebar akan menghadap utara dan selatan; bagian barat dan timur memiliki sisi lebih panas, terutama saat pagi (sekitar jam 1012) dan sore hari (sekitar jam 3-5) - lebih efektif kegiatan yang membutuhkan sinar matahari. Aspek pengudaraan, dapat dibelokkan oleh pepohonan sekitar, maka dari itu bukaan dari utara, selatan, barat, timur kemungkinan tidak masalah. Aspek aliran pembuangan air, air mengalir kearah selatan karena dekat dengan sungai.

\section{Program Proyek}

Dengan berdasarkan isu permukiman kumuh, maka untuk itu adanya upaya memperbaiki lingkungannya, dengan adanya program proyek seperti;

a. Rumah Susun

Pilihan untuk permukiman yang kumuh, karena tidak adanya ruang terbuka dan hunian yang kurang layak atau bahkan tidak layak. Dengan adanya hunian vertikal ini bisa menciptakan ruang terbuka.

b. Ruang Terbuka Hijau

Dengan adanya hunian vertikal maka, sebagian lahan yang dahulu permukiman bisa digunakan sebagai ruang terbuka hijau sebagai area resapan, dan membantu meningkatkan kualitas udara, selain itu bisa menjadi tempat hiburan bagi masyarakat sekitar.

c. Sistem Berkelanjutan

Dengan adanya kegiatan berhuni, maka adanya limbah yang dihasilkan banyak, maka dari itu baiknya adanya kegiatan berkelanjutan seperti mengolah sampah anorganik, menggunakan kembali air limbah (greywater), ada pun memanfaatkan air hujan dan memanfaatkan sinar matahari sebagai energi matahari d. Ekonomi, Sosial dan Budaya 
Adanya tempat yang bisa mendukung kegiatan social-budaya, seperti adanya tempat untuk kegiatan pada saat hari raya. Selain itu menyediakan untuk kegiatan perekonomian, dengan begitu bisa meningkatkan perekonomian masyrakat yang tinggal, salah satu caranya dengan menjual hasil olahan sampah anorganik. Hasilnya berupa seprti tas atau kantong belanja, dompet, taplak meja, dan lainnya.

\section{Konsep Perancangan dan Gubahan Massa}

Konsep dari bangunan ini berawal dari masalah atau isu yang diangkat. Merubah lingkungan menjadi baik salah satunya adanya ruang terbuka hijau pada lingkungan tersebut. Dengan cara menggantikan tempat tinggal masyarakat menjadi rumah vertical. Menjadikan rumah vertical dengan tujuan agar adanya ruang terbuka. Ruang terbuka hijau maupun bukan hijau, tujuan agar adanya aliran udara yang bebas dan dapat sinar matahari yang cukup. Menggunakan konsep dasar dari Greenship Home V.1.0 yang memiliki konsep rumah ramah lingkungan.

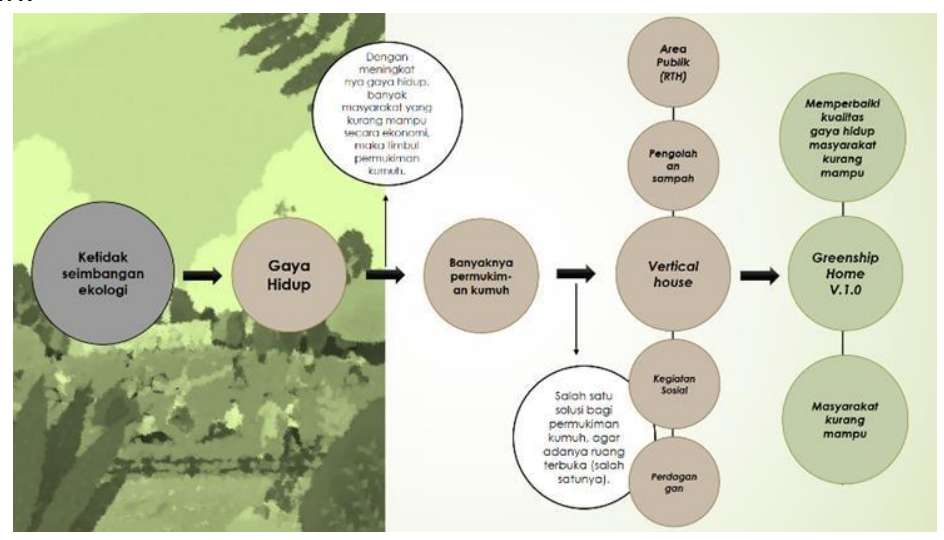

Gambar 4. Bagan Analisis Konsep Perancangan Sumber :dokumen pribadi, 2021

Greenship Home V.1.0 memiliki kriteria dalam mendesain hunian untuk mewujudkan rumah ramah lingkungan (green home) (1) pengaturan mengenai tata guna lahan yang memuat mengenai area hijau, infrastruktur, aksesbilitas, pengendalian hama, upaya pengurangan emisi, dan pengurangan limpasan air hujan; (2) efisiensi energi dan konservasi yang memuat mengenai pentingnya pencahayaan dan pengudaraan secara alami serta mendorong penggunaan elektronik hemat energi, dan penggunaan energi terbarukan; (3) mengenai konservasi air dimana membicarakan mengenai hemat dalam penggunaan air serta bisa mengolah air limbah dan upaya penggunaan air hujan sebagai air bersih; (4) sumber dan siklus material dimana bermaksud untuk adanya upaya penggunaan material ramah lingkungan; (5) kualitas udara dan kenyamanan udara upaya dalam pengendalian sirkulasi udara bersih serta pencahayaan alami; (6) manajemen lingkungan bangunan dimana membicarakan mengenai sistem berkelanjutan.

Gubahan massa bangunan mengikuti tapak, yang memanjang ke arah timur dengan sisi barat merupakan tampak depan. Pada tahap pertama, Bentuk dasar bangunan berdasarkan tapak, memanjang kebelakang ke arah timur. Dimana bagian terpanas memiliki bagian lebar bangunan, menghindari panasnya matahari, namun bisa dimanfaatkan. Pada tahap kedua, Terbagi kedalam 3 bagian. Untuk memecah udara, agar udara bisa masuk dalam bangunan, selain itu membagi kedalam fungsi bangunan. Pada tahap ketiga, 2 bagian belakang untuk menghindari kebisingan yang terjadi pada jalan besar selain itu agar pergerakan udara bisa bebas, bagian depan terkait dengan fungsi yaitu digunakan sebagai kegiatan umum. 


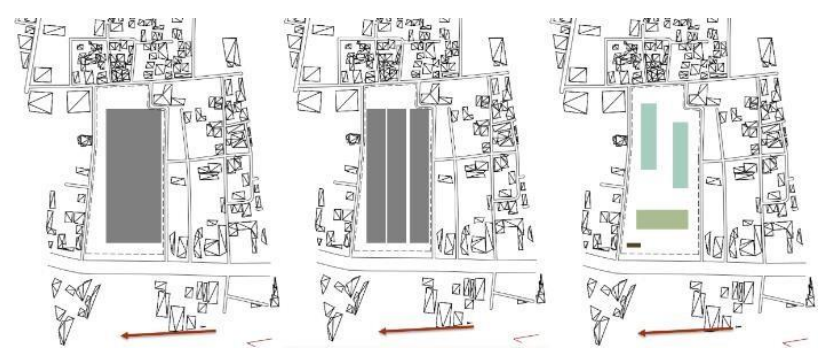

Gambar 5. Proses Gubahan Massa (I)

Kiri : pertama, tengah : kedua, kanan : ketiga

Sumber :dokumen pribadi, 2021

Memasuki tahap keempat, pada bagian belakang (timur) area hunian merupakan service, berkaitan dengan sampah organik, dan pembuangan limbah yang lebih dekat dengan area hunian, limbah cair dan limpasan air hujan mengalir ke arah selatan. Tahap kelima, area perkerasan untuk parkir dibuat seminim mungkin, agar tidak memantulkan panas maka hanya 1 area yang menghadap barat. Tahap keenam, sisa lahan dari tapak berupa area hijau sebagai produsen oksigen, menurunkan suhu, paru-paru wilayah, dan area resapan.

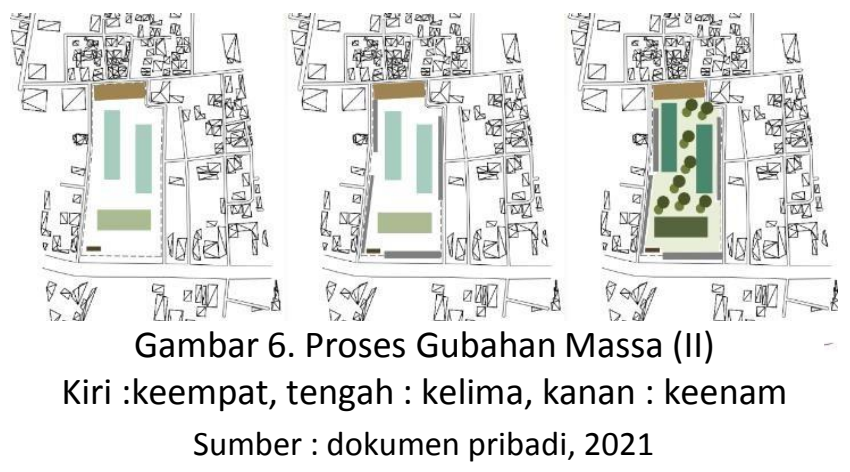

Setelah melakukan pertimbangan dan perombakan, pada tahap ketujuh bentuk akhir bangunan, digeser agar matahari dan anginya bisa masuk kedalam bangunan. Begitu pula dengan cahaya mataharinya, pada tahap ini fungsi bangunan bagian barat merupakan fungsi bersama, lalu timur merupakan hunian. Pada tahap kedelapan rencana peletakan dan pemakaian solar panel untuk bangunan.

\section{Zonasi Tapak dan Bangunan}
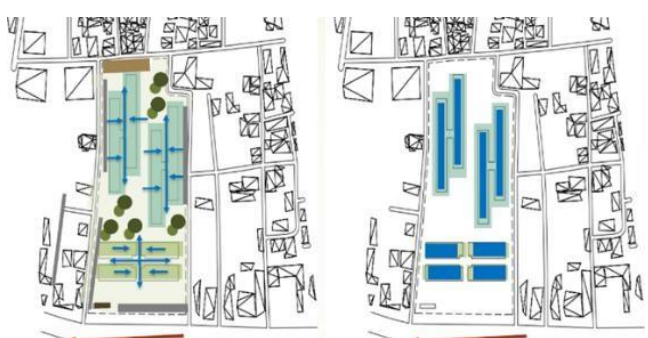

Gambar 7. Proses Gubahan Massa (III)

Kiri :ketujuh, kanan : kedelapan

Sumber : dokumen pribadi, 2021

Zonasi tapak terbagi atas publik, semi privat, privat, dan servis. Publik sendiri terdiri dari bangunan umum atau serba guna yang digunakan oleh masyarakat sekitar untuk kegiatan umum. Semi private dan private tergabung, karena sudah mulai memasuki wilayah hunian yag terdapat fasilitas umum yang diperuntukan untuk umum. Area service terdiri dari tempat untuk sampah dan parkir pemiliki hunian. 


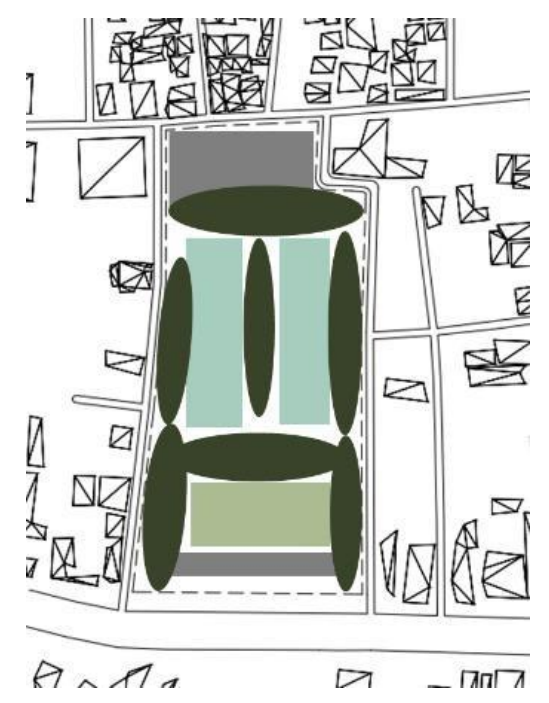

Gambar 8. Zonasi pada tapak

Sumber : dokumen pribadi, 2021

Pada zonasi bangunan terbagi dari 2 jenis fungsi. Fungsi pertama untuk hunian (di semi privat dan privat). Bangunan hunian memiliki 5 lantai, dengan formasi lantai pertama untuk fasilitas umum dan 4 lantai sisanya untuk hunian. Fungsi kedua terletak di area publik,yang fungsinya untuk bersama (serba guna).

\begin{tabular}{|c|c|c|c|}
\hline Area & \multicolumn{2}{|c|}{ Jumlah tower / Kebutuhan } & Luas lt.dasar \\
\hline Hunian & \multicolumn{2}{|c|}{$\begin{array}{c}2 \text { tower (@105 unit hunian) } \\
5 \text { lantai } \\
\text { Lantai dasar : fasilitas } \\
\text { umum/usaha } \\
\text { Lantai } 2-5: \text { unit kamar. } \\
\text { Per lantai hunian terdiri dari : } \\
\text { Tipe studio ( } 2 \text { unit) }=3 \times 9 \mathrm{~m} \\
\text { Tipe } 1 \text { kamar ( } 3 \text { unit) }=4 \times 9 \mathrm{~m} \\
\text { Tipe } 2 \text { amar (16 unit) }=6 \times 9 \mathrm{~m} \\
\text { Total per lantai }=21 \text { unit }\end{array}$} & $\begin{array}{c}2.480 \mathrm{~m} 2(@ 1.240 \mathrm{~m} 2) \\
\mathrm{KDB} 60 \%=8.837 \mathrm{~m} 2\end{array}$ \\
\hline $\begin{array}{l}\text { Pengelola } \\
\& \text { a } \\
\text { Serba Guna }\end{array}$ & \multicolumn{2}{|c|}{-1 tower , 2 lantai } & $\begin{array}{c} - \pm 64 \mathrm{~m} 2(+ \text { sirkulasi } 30 \% \\
= \pm 84 \mathrm{~m} 2)- \text { It } 1 \text { \& It } 2 \\
- \pm 1.380 \mathrm{~m} 2(+ \text { sirkulasi } \\
30 \%= \pm 1.800 \mathrm{~m} 2)\end{array}$ \\
\hline \multirow{2}{*}{$\begin{array}{l}\text { Service } \\
\text { (Parkir dan } \\
\text { TPS) }\end{array}$} & Mobil & 78 slot & $1.170 \mathrm{~m} 2$ \\
\hline & $\begin{array}{l}\text { Motor \& } \\
\text { sepeda }\end{array}$ & 196 slot & $392 \mathrm{~m} 2$ \\
\hline Hijau & \multicolumn{3}{|c|}{$\begin{array}{c}5.891 \mathrm{~m} 2 \\
\text { KDH } 40 \%=5.891 \mathrm{~m} 2\end{array}$} \\
\hline Total & \multicolumn{3}{|c|}{$\begin{array}{c} \pm 4.869 \mathrm{~m} 2 \\
(\text { sisa } \pm 3.968 \mathrm{~m} 2)\end{array}$} \\
\hline
\end{tabular}

Gambar 9. Kebutuhan ruang

Sumber : dokumen pribadi, 2021

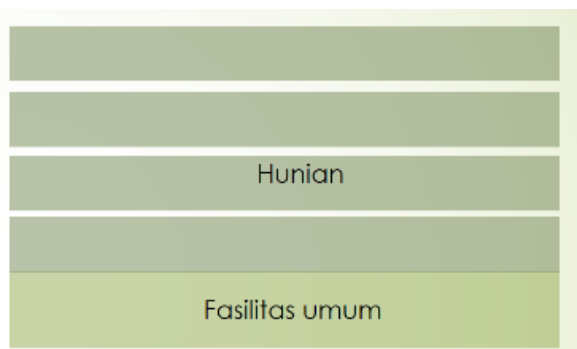

Gambar 10. Zonasi vertikal gedung hunian

Sumber : dokumen pribadi, 2021 
Zoning Vertikal Gedung Serba Guna

Area serba guna

Fasilitas umum / Area pengelola

Gambar 11. zonasi vertikal gedung serba guna

Sumber : dokumen pribadi, 2021

\section{Deskripsi gedung rumah susun}

Gedung rumah susun memiliki desain persegi panjang sederhana yang menyesuaikan fungsi, dengan tipologi hunian. Gedung ini memiliki total 5 lantai, yang memiliki 2 fungsi; yaitu pada lantai dasar dipergunakan sebagai fasilitas usaha, klinik, apotik dan penitipan anak, dan tempat untuk pengolahan sampah anorganik; lantai dua hingga lantai 5 sebagai hunian; lalu ada lantai ruang bawah tanah (basement) yang diperuntukan untuk servis. Area atap untuk reservoir atas dan atap selain sebagai pelindung juga sebagai penyangga panel surya.

Gedung rumah susun ini memiliki tiga tipe unit. Semua unit masing-masing memiliki kamar tidur, kamar mandi, dapur dan ruang makan. Tiga tipe unit tersebut yaitu;

a. Tipe studio yang memiliki ukuran 3x9m, namun tanpa tempat cuci jemur dan balkon;

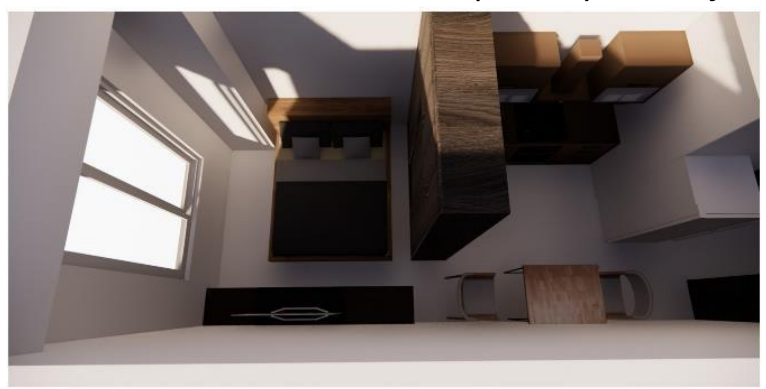

Gambar 12. Interior tipe studio -Kamar tidur dan area dapur dan ruang makan Sumber : dokumen pribadi, 2021

Tipe studio berkapasitas minimal satu orang dan maksimal dua orang. Tipe studio ini memiliki jumlah2 unit dalam satu lantai, yang berarti dalam satu gedung memiliki total 10 unit.

b. Tipe satu kamar yang berukuran $4 \times 9 m$, tidak memiliki balkon ;

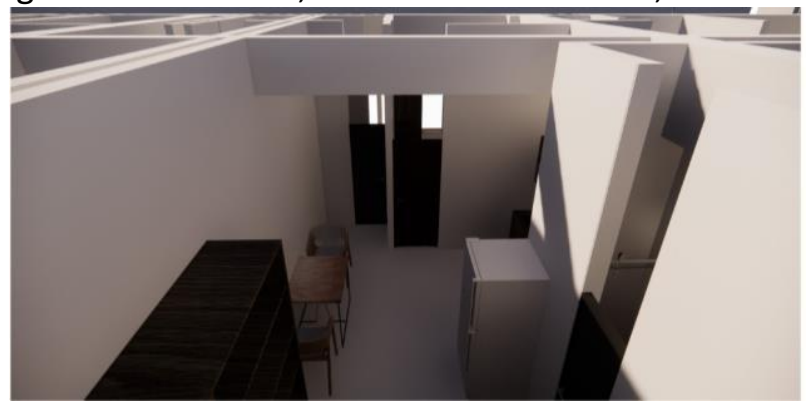

Gambar 13. Interior tipe satu kamar Area dapur dan ruang makan dan kamar tidur Sumber : dokumen pribadi, 2021 


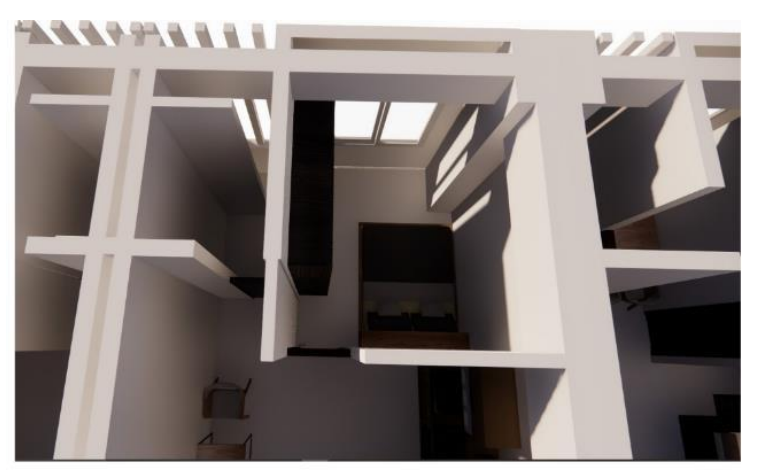

Gambar 14. Interior tipe satu kamarkamar tidur Sumber : dokumen pribadi, 2021

Tipe satu kamar berkapasitas minimal satu orang dan maksimal dua orang. Tipe satu kamar ini memiliki jumlah 3 unit dalam satu lantai, dalam satu gedung memiliki total 15 unit.

c. Tipe dua kamar yang berukuran $6 \times 9 \mathrm{~m}$ serta memiliki balkon.

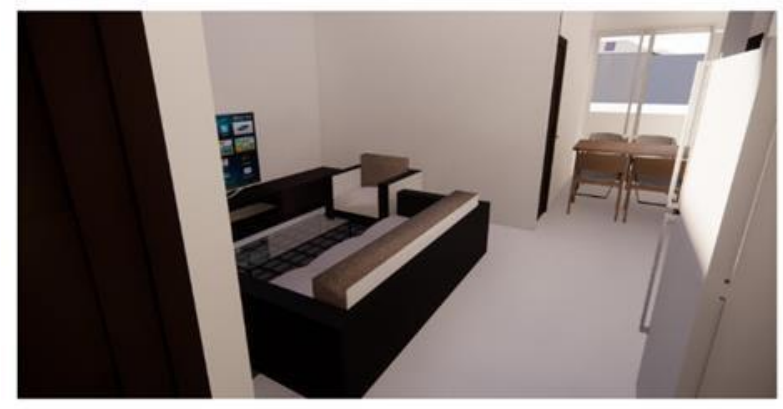

Gambar 15. Interior tipe dua kamar Ruang tengah dan ruang makan Sumber : dokumen pribadi, 2021

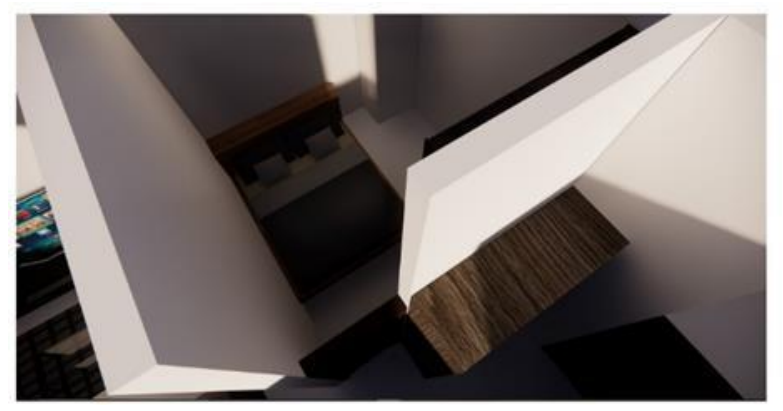

Gambar 16. Interior tipe dua kamar Kamar tidur 2

Sumber : dokumen pribadi, 2021

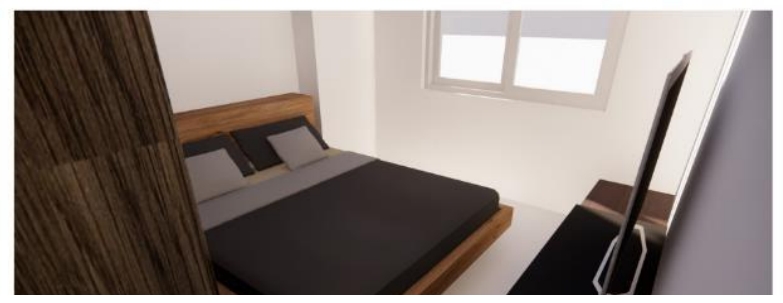

Gambar 17. Interior tipe dua kamar

Area dapur dan ruang tengah (kiri) dan kamar tidur 1 (kanan) Sumber : dokumen pribadi, 2021 
Tipe ini terdiri dari dua ruang tidur yang masing-masing berkapasitas minimal satu orang dan maksimal dua orang; ruang tengah atau ruang keluarga dengan kapasitas empat hingga maksimal lima orang; ruang makan; dapur; kamar mandi; dan area cuci dan jemur; serta balkon. Tipe ini berkapasitas minimal dua orang dan maksimal lima orang. Tipe satu kamar ini jumlah 16 unit dalam satu lantai, dalam gedung memiliki total 64 unit tipe dua kamar.

Dalam satu gedung rumah susun terdapat 105 unit yang terdiri dari 10 unit tipe studio; 15 unit tipe satu kamar; dan 64 unit tipe dua kamar.

Lantai dasar dipergunakan untuk kebutuhan umum seperti;

a. Fasilitas usaha yang disediakan berupa kios dengan ukuran $6 \times 9 \mathrm{~m}$. Kios ini disediakan bertujuan untuk para penghuni yang memiliki usaha seperti warung makan, atau usaha toko klontong dan lain sebagainya untuk memenuhi kebutuhan para penghuni yang lain selain meningkatkan perekonomian pemilik;

b. Klinik, apotik dan penitipan anak hal ini agar gedung hunian tetap menjaga kebersamaan dengan cara menyediakannya di salah satu gedung hunian. Klinik menyediakan dua kamar periksa yang masing-masing berkapasitas 1 dokter dengan 1 pasien serta 2 pendamping; ruang tunggu dan resepionis yang menyambung langsung dengan apotik. Penitipan anak ini ada bertujuan agar para ibu atau orang tua yang bekerja tidak khawatir. Maka dari itu dengan adanya tempat ini juga diharapkan anak-anak bisa bersosialisasi dengan sebayanya;

c. Pengolahan sampah anorganik bertujuan untuk memanfaatkan sampah anorganik sebagai barang yang bisa digunakan kembali seperti tas, taplak meja, dompet atau wadah lainnya yang berguna untuk keseharian. Sampah anorganik ini didapat dari sampah sehari-hari para penghuni seperti pembungkus pelembut pakaian, pembungkus deterjen, dan lain-lain termasuk botol bekas atau plastic lainnya yang bisa diolah dan bisa diperjual belikan kembali dan juga mengurangi beban tempat pembuangan sampah, agar tidak terlalu menumpuk; selain itu dengan mengolah sampah anorganik mengajak para penghuni agar bisa hidup berkelanjutan serta memiliki keterampilan dalam menjahit ataupun mendesain sampah anorganik menjadi sesuatu yang berguna, hasilnya berupa tas atau kantong belanja, dompet, taplak meja, dan lain sebagainya yang berguna untuk berumah tangga.

\section{Ruang bawah tanah (basement)}

a. Ruang bawah tanah ini berisikan ruangan untuk servis yang terdiri dari ruang shaft, Ground Water Tank (GWT) ,genset, dan septic Tank. Ruang-ruang ini dil etakan di bawah tanah agar tidak mengganggu dan sekaligus agar orang yang ingin memperbaiki dengan mudah jika ada kendala.

b. Ruang genset ini di peruntukan untuk penggunaan listrik pada kebutuhan lantai dasar sebagai penyedia fasilitas umum bagi penghuni. Serta adanya alat (interver) sebagai pengganti energi tenaga surya menjadi listrik yang digunakan untuk lantai dasar.

c. Ruang shaft yang terdiri dari pipa-pipa untuk air keatas maupun untuk kebawah. Ruang GWT berdampingan dengan pompa dan filter. Hal ini selain sebagai penyimpanan air bersih, pompa dan filter sebagai pengolahan air hujan dan greywater (air bekas cucian) yang bisa dimanfaatkan kembali sebagai air bersih, yang digunakan untuk air cuci dan air toilet. Selain itu septic tank sebagai wadah pengolahan limbah kotoran atau tinja.

Gedung ini ditopang oleh kolom berukuran $80 \times 80 \mathrm{~cm}$ dengan balok induk berukuran $40 \times 75 \mathrm{~cm}$ dan balok anak $25 \times 50 \mathrm{~cm}$. Rangka atap memakai material double cannal $\mathrm{C}$ berukuran $15 \mathrm{~mm}$ dengan penutupnya memakai galvalum dan panel surya, dengan model atap limas. Tampak bangunan memakai finishing batu bata sebagai pemanis, dan adanya kisi-kisi rangka pada bagian ruang tertentu. Kisi-kisi ini berfungsi sebagai penutup bagian balkon, namun masih mendapat sinar matahari. 


\section{Deskrip gedung serba guna}

Gedung serba guna ini diperuntukan untuk para penghuni, selain itu juga untuk para warga sekitar yang sekiranya membutuhkan. Gedung serba guna ini berisi ruang pengelola hunian, mushola, area rumah makan yang terdiri dari 4 kios, lapangan badminton, dan balai serba guna.

Balai serba guna ini bisa digunakan untuk acara atau kegiatan yang bersifat internal maupun eksternal, dimana yang menggunakan boleh selain para penghuni. Balai ini bisa untuk acara keagamaan, hari raya, pernikahan, maupun acara adat yang membutuhkan upacara khusus.

Gedung ini memiliki kolom berukuran $40 \times 40 \mathrm{~cm}$ dengan balok induk berukuran $40 \times 75 \mathrm{~cm}$ dan balok anak $25 \times 50 \mathrm{~cm}$. Pada dasarnya bagian atap memiliki reservoir atas, dan rangka atap memakai besi double cannal $C$ berukuran $15 \mathrm{~mm}$ dengan penutup rangka atap memakai galvalum, dengan model limas disertai panel surya.

\section{Pemakaian Energi Terbarukan dan Sistem Berkelanjutan}

Proyek ini memakai salah satu engeri terbarukan yaitu memakai sinar matahari sebagai listrik memakai alat panel surya, dimana energi ini digunakan pada lantai dasar untuk gedung hunian dan digunakan seluruh bangunan di gedung serba guna, selebihnya agar menggunakan listrik biasa, yakni PLN. Ini disebabkan karena, terbatasnya antara jumlah kebutuhan dengan jumlah penyediaan solar panel yang di gunakan. Solar panel hanya diletakan diatas atap, secara jumlah listrik atau daya kurang memadai jika digunakan untuk seluruh bangunan, kecuali pada bangunan serba guna, maka dari itu pada gedung hunian yang menggunakan listrik dari tenaga surya hanya pada lantai dasar yaitu pada kios-kios atau fasilitas umum.

Hidup berkelanjutan berkaitan dengan hemat energi, dimana dalam upayanya memiliki tujuan yang sama. Dalam penggunaan kembali air limbah dan air hujan, melakukan penghematan energi. Hal ini juga mengurangi pengurangan limpasan air hujan yang bisa menyebabkan banjir.

Pemanfaatan sampah anorganik yang bisa diolah menjadi barang berguna, berkaitan dengan hemat dalam mengolah sampah anorganik yang sulit untuk terurai, digunakan kembali sebagai tas, dompet, taplak meja dan lain sebagainya.

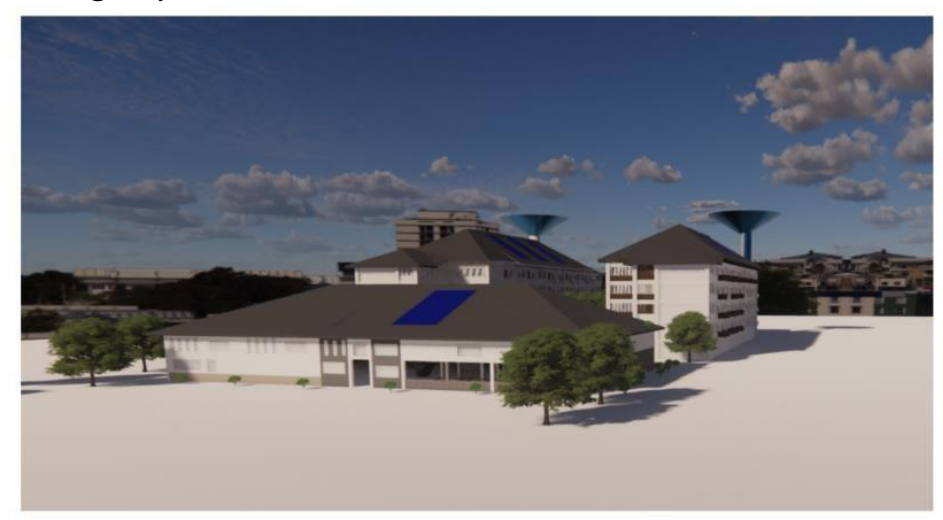

Gambar 18. Eksterior Bangunan

Gedung serba guna (depan) dan Gedung hunian (belakang)

Sumber : dokumen pribadi, 2021

\section{KESIMPULAN DAN SARAN}

\section{Kesimpulan}

Pada proyek ini, memiliki permasalahan yang sudah lama terjadi dan sering terjadi, namun hingga sekarang baru sedikit perubahan yang terjadi, maka diharapkan dengan adanya proyek ini bisa 
merubah sesuatu yang belum terselesaikan melalui tema 'beyond ecology' . Beyond Ecology sendiri menurut penulis, memiliki arti dimana menciptakan suatu tempat apapun fungsinya, yang selain untuk manusia juga harus memperhatikan alam.

Proyek ini merupakan salah satu cara untuk menyelesaikan permasalahan ekologi mengenai permukiman kumuh. Proyek ini diharapkan bisa membantu mengurangi permasalahan permukiman kumuh. Salah satu caranya dengan adanya rumah susun dan ruang terbuka bisa membantu mengurangi permasalahan keseimbangan ekologi, edngan menerapkan metode greenship home yang berprinsipkan pada penghematan energi, dimulai dengan tidak lagi bertempat tinggal dengan tidak sehat atau kumuh, karena memiliki prinsip mengutamakan ruang terbuka hijau, dengan itu juga upaya dalam pengolahan air limbah dan air hujan yang bisa dimanfaatkan kembali menjad air bersih dan bisa digunakan kembali, adanya upaya lebih menfaatkan pengudaraan alami dan pencahayaan alami dlama kegiatan sehari-hari, dan juga hidup dengan sistem berkelanjutan seperti adanya gerakan untuk pengolahan sampah anorganik yang dihasilkan sampah rumah tangga berupa plastic bekas detergen, makanan, atau bahan anorganik lainnya yang diolah dan menghasilkan berupa tas atau kantung belanja, dompet, taplak meja dan sebagainya yang bermanfaat dan memiliki daya jual.

\section{Saran}

Penulis berharap proyek seperti ini bisa menjadi pertimbangan pemerintahan kota Solo untuk memperbaiki permukiman kumuh bagi masyarakat yang hidup kurang layak ataupun tidak layak. DIsamping itu, adanya upaya mulai menggalakan penghematan energi dalam hunian, dan mulai hidup dalam system berkelanjutan.

Perancangan ini perlu dilakukannya penelitian lagi dan bisa dikembangkan secara desain maupun analisis-analisis yang telah dikerjakan oleh penulis, serta tidak di anjurkan jurnal ini sebagai acuan atau referensi sepenuhnya.

\section{REFERENSI}

BAPPPEDA Kota Surakarta. (2017). Rencana Tata Ruang Wilayah Kota Surakarta Tahun 2011-2031 [Electronic Version]. Bapppeda : Surakarta

Blog Teknik Planologi. (2017). 6 Pengertian Pembangunan Berkelanjutan Menurut Para Ahli. Retrieved 03 Juli, 2021, from http://www.radarplanologi.com/2015/11/pengertian-pembangunanberkelanjutan.html

Dinas Pekerjaan Umum dan Penataan Ruang. (2017). Peta Informasi Tata Ruang Infrastruktur dan Perancanaan.Retrieved 18 Februari 2021, from https://dpupr.surakarta.go.id/sitepu/front_solo/aplikasi/aplikasi_intip

Green Building Council Indonesia. (2014). Greenship Homes version 1.0. [Electronic Versioin]. Green Building Council Indonesia: Jakarta

Kompas. Com. (2008) . Cara Menghemat Energi. Retrieved 14 Agustus, 2021, from https://www.kompas.com/skola/read/2020/09/11/180000469/cara-menghemat-energi

Lembaran Negara Republik Indonesia Tahun 1985 Nomor 3318. Jakarta

Setyawan, D. (2009). Energi. Yogyakarta : Kanisius

Undang-undang Republik Indonesia Nomor 16 Tahun 1985. Tentang Rumah Susun. 31 Desember 1985.

World Commission on Environment and Development. (1987). Pembangunan Berkelanjutan . Britania Raya : Oxford University Press

Yayasan Buddha Tzu Chi Indonesia. (2021). Hemat Energi. Retrieved 14 Agustus, 2021, from http://www.tzuchi.or.id/ruang-hijau/hemat-energi/21 
